\title{
Longitudinal Examination of Learning and Memory in Rats Following Adolescent Exposure to 3,4-Methylenedioxymethamphetamine or 5-Methoxy-N,N-Diisopropyltryptamine
}

\author{
David M. Compton*, Kerri L. Dietrich, Peniel Esquivel, Corina Garcia \\ Department of Psychology, Donnelley Behavioral Neuroscience Laboratory, Palm Beach Atlantic University, West Palm Beach, \\ FL, USA \\ Email: ^david_compton@pba.edu
}

How to cite this paper: Compton, D.M., Dietrich, K.L., Esquivel, P. and Garcia, C. (2017) Longitudinal Examination of Learning and Memory in Rats Following Adolescent Exposure to 3,4-Methylenedioxymethamphetamine or 5-Methoxy-N,N-Diisopropyltryptamine. Journal of Behavioral and Brain Science, 7, 371-398.

https://doi.org/10.4236/jbbs.2017.79028

Received: July 18, 2017

Accepted: September 8, 2017

Published: September 11, 2017

Copyright $\odot 2017$ by authors and Scientific Research Publishing Inc. This work is licensed under the Creative Commons Attribution International License (CC BY 4.0).

http://creativecommons.org/licenses/by/4.0/

\begin{abstract}
A drug of abuse, Foxy or Methoxy Foxy gained popularity among recreational users as an alternative to MDMA (Ecstasy). Considerable research into the consequences of MDMA use is available, yet much remains unknown about the neurobiological consequences of Foxy use. In addition, research into the long-term neuropsychological repercussions associated with these two compounds remains incomplete. The goal of the present research was to explore the effects of MDMA or Foxy on cognitive processes associated with adolescent exposure considered over much of the lifespan. Here we investigated whether the reported effects following adolescent exposure resolved in early adulthood or continued throughout life. The protocol involved repeated doses of either MDMA or Foxy during the period defined as mid-adolescence (postnatal days 34 - 46) in rats, followed by the use of four series of learning and memory tasks repeated at different points in the rodent lifespan. At four time points in adulthood, the animals were trained and tested on a on a series of spatial and nonspatial memory tasks designed to assess the impact and severity of Foxy and MDMA. Oddly, MDMA-treated rats were impaired on a step down passive avoidance task. The performance of the drug-treated rats was markedly inferior to that of the control animals on more demanding water maze tasks, with some results suggesting a lack of flexibility in adapting to changing task demands. MDMA rats were the most impaired. While some persistent cognitive deficits were found, no significant group differences in serotonin or dopamine levels were found in any of the measured regions of the brain changes, cortical or subcortical. These results provide evidence for compromised neurocognition that continues long after drug exposure in the
\end{abstract}


absence of any discernable changes in neurotransmitter levels. Several possible physiological and neurochemical mechanisms associated with these compounds requiring further study are also outlined.

\section{Keywords}

MDMA, Ecstasy, 5-MeO-DIPT, Foxy, Spatial Learning, Development, Memory

\section{Introduction}

While adolescence is time of considerable neurodevelopmental change, it is also characterized as a period marked with significant risk-taking behavior [1] [2]. One of such set of adolescent risk-taking behaviors involves the use of "club drugs" such as 3,4-Methylenedioxymethamphetamine (MDMA, "ecstasy") [3], a drug with a variety of potential neurotoxic effects [4]. Owing to the fact that the limbic areas and prefrontal cortex continue to undergo considerable maturational change, the adolescent brain is particularly susceptible to the putative neurotoxic effects associated with MDMA use [3] [5] [6] [7].

The recreational use of MDMA is associated with reported effects including euphoria [8], enhanced confidence [9], and deeper pro-social feelings and empathy for others leading to its characterizations as an empathogen [10]. Additionally, a number of neuropsychological deficits associated with MDMA have been reported [11] [12] [13]. Various processes have been implicated, including excitotoxicity and oxidative stress [14], yet full molecular changes driving these neurotoxic effects remain to be fully elucidated [15]. The consensus is that there is an MDMA-induced neurodegeneration of serotonin terminals [15] [16] and that this compound produces a reduction in CNS serotonin and dopamine levels in areas of the brain [17] central for normal learning and memory to occur [18].

Indolealkylamines (IAA) are a class of chemical derivatives of 5-hydroxytryptamine (5-HT, serotonin) [19], which principally act on 5-HT systems [20]. As a neurotransmitter, 5-HT has been implicated in a number of processes including attention, cognition, and memory, dreaming, and pain regulation [21]. Some IAAs have been used for medical purposes, with others used in religious rites [22]. Unfortunately, as a class which include compounds such as LSD, psilocybin, they have considerable potential for recreational abuse and are classified under the Controlled Substances Act. Of interest here, one drug, 5-methoxy-N, $\mathrm{N}$-diisopropyltryptamine (5-MeO-DIPT; Foxy), has properties similar to other tryptaminergic hallucinogens [23] leading recreational users of MDMA and other compounds to experiment with it [24].

Research into the effects of Foxy with rodent models have led to reports of Foxy-associated deficits [24] [25] [26] [27]. While the specific effects associated with exposure to Foxy remains to be elucidated, the available evidence is suggestive of deficits primarily associated with compromised attentional processes and 
response perseveration [28]. Response perseveration is considered distinct from motor or motivational deficits and is considered an indicator of impaired cognition. Such impairments, when found, are associated with a disruption in the ability to flexibly change behavior(s) as task demands change. As such, response perseveration involves a maladaptive change in executive function [29].

Although the available evidence is considerable, most of the measures of behavioral performance occur within the confines of a short-term investigation or cross-sectional comparison [30]. In humans, both cross-sectional and, more rarely, longitudinal studies have suggested MDMA associated deficits on a variety of assessments of learning and memory performance [13]. Reported MDMA-associated impairments involve multiple cognitive domains, including executive function and planning, working memory, and retrospective as well as prospective memory [11] [31]-[37]. Unfortunately, when considered from a methodological viewpoint, definitive conclusions derived from this body of research are problematic [30]. Indeed, the quasi-experimental nature of most of the reports are limited by the issues associated with the use of pre-existing groups, selection biases, and such confounding variables as polydrug use. For example, there are reports of equivalent cognitive deficits when ecstasy and nonecstasy drug users are matched by other types of drug use for comparison [38] [39] [40]. Nonetheless, other researchers have reported greater cognitive deficits among ecstasy users [35] [41]. Thus, given the legal (i.e., US DEA Schedule I) and ethical constraints (US HHS, 45 C.F.R. $\$ 46,2009$, [42]) associated with administering MDMA and other club drugs to humans, animal models allow for the critical assessment of the neurotoxic effects these compounds without the methodological shortcomings associated much of the work with humans [43].

Rat adolescence is defined as the period from the 21st postnatal day (PND) until about PND 60 [44]. Further, rat adolescence can be subdivided into mid adolescence (PNDs 34 to 46) and late adolescence (PNDs 46 to 59). The two developmental periods are considered analogous to periadolescence and late adolescence/early adulthood [44]. Using this framework as a model of neuropsychological development, comparative evaluation and extrapolation to humans is possible [7]. Thus, the use of adolescent rats permits the examination into the developmental consequences associated with two drugs of abuse at various points in biological and neurocognitive development.

Developmental investigations of the effects MDMA, suggest the age of exposure to be a critical variable [45]. For example, Broening and colleagues found that rats exposed to MDMA on PND 1 through 10 were unimpaired when tested on sequential and spatial learning tasks as adults. However, MDMA exposure on PND 11 through 20 resulted in dose-dependent learning and memory deficits when tested on a series of tasks at PNDs 59 through 82 [46]. Such results are consistent with other reports suggesting that the neurotoxic effects of neonatal or perinatal MDMA exposure generally are less severe than that observed in adult animals [47] [48] [49] [50] [51]. Generally, a long-term decrease in the le- 
vels of 5-HT and 5-HIAA is seen after adolescent exposure of MDMA alterations in cognitive performance have been reported in the absence of definitive alterations to serotonergic systems (see [45] [52], for reviews).

Despite efforts to reduce the use MDMA, including the introduction of more effective restrictions in precursor control [53], the drug remains an issue of concern [54]. Indeed, a decline in perceived risk of harm has been observed in a survey of teens [55]. Further, although a slight decline since 2003 has been observed, in 2015 roughly $7 \%$ of adults have used MDMA, with peak use during early (i.e., 18 - 25) adulthood [56]. Noteworthy, reports of the consequences of recreational use of ecstasy point to severe toxicity, symptoms of which include impairments of prospective and retrospective memory [12] and a variety of physiological effects such as hyperthermia and hypertension [57] [58].

While the studies discussed here are suggestive, only limited data exists on the long-term consequences associated with MDMA or Foxy use, with little information available that longitudinally tracks the effects of these compounds across an extended period of time. Generally, the use of assessments having occurred at a specific time point in the life of the research subject, and using different methodologies, make age-related progression of deterioration associated with these compounds, if any, a challenge. Although there is evidence of persistent deficits following adolescent exposure of these two compounds [24] [27], including a few reports of MDMA or Foxy associated deficits in a rodent rave paradigm [28] [59], no research has extended the testing period beyond a few months following the drug exposure period. As noted earlier, although a number of cross-sectional and some longitudinal investigations with humans as subjects suggest lingering deficits in cognitive performance following MDMA abuse [13], such studies typically have substantial methodological limitations [30]. Our protocol involved repeated doses of either MDMA or Foxy during the period defined as adolescence in rats (i.e., PNDs 34 - 59), followed by the use of four series of learning and memory tasks repeated at different points in the rodent lifespan. Therefore, the goal of the present investigation was to examine further the effects of MDMA or Foxy on cognitive processes associated with adolescent exposure across the lifespan. Specifically, here we considered whether the reported effects following adolescent exposure resolved in early adulthood or continued throughout life.

\section{Method}

\subsection{Subjects}

Twenty-one male Long-Evans rats Wistar rats ( 100 g at first injection) were used to assess the long-term effects of MDMA or Foxy. The rats were individually housed in standard stainless-steel cages under standard laboratory conditions of lighting (07:00-19:00 $\mathrm{h})$, with an ambient temperature $\left(19^{\circ} \mathrm{C}-21^{\circ} \mathrm{C}\right)$ and humidity between $45 \%$ and $50 \%$. Food and water were freely available throughout the investigation. After a one week facility acclimation period and prior to 
the beginning of the experiment, the animals were randomly assigned to one of two drug treatment conditions or a saline control group. From 35 to 45 days of age, the rats were exposed to MDMA, Foxy, or a corresponding volume of saline. Behavioral testing occurred in adulthood when the rats were 111 days old and had been drug free for 66 days. Behavioral testing included four multi-day assessment periods beginning at PNDs 111, 219, 327, and 435. Data collection was performed during the light period (12:00-15:00 h). All procedures were conducted according to the guidelines approved by the Institutional Animal Care and Use Committee of Palm Beach Atlantic University utilizing standards outlined in the Guide for the Care and Use of Laboratory Animals [60].

\subsection{Drugs and Drug Administration}

Drug exposure began when the rats were in the mid-adolescent period of development (i.e., 35 days old). The rats received a total of six injections of MDMA (5 $\mathrm{mg} / \mathrm{kg}$; Sigma-Aldrich, St. Louis, MO), Foxy ( $5 \mathrm{mg} / \mathrm{kg}$; Biosynth International, Naperville, IL), or a corresponding injection volume of isotonic saline. Drugs were injected intraperitoneally (IP) at a constant volume of $2 \mathrm{ml} / \mathrm{kg}$. The injections were delivered at a rate of one injection session every 48 hours. Initial behavioral testing occurred in adulthood when the rats were 111 days old and had been drug free for 66 days.

\subsection{Apparatus-Morris Water Maze (MWM)}

All variations of spatial and nonspatial assessments took place in a circular white acrylic plastic swimming pool $183 \mathrm{~cm}$ in diameter. Depending on the assessment, different extra-maze cues and escape parameters were employed. With the exception of the cued water maze phase of the experiment (see following), the depth of the water was held constant at $30 \mathrm{~cm}$ and made an opaque white color using a nontoxic water-based paint (Sargant Art, Hazelton, PA). The swimming pool and associated cues were located in a quiet testing room approximately 36.88 square meters in size. The number of external stimuli available to aid navigation when viewed from the surface of the pool was limited by the use of white curtain panels that surrounded the pool and obscured distal cues on two of four walls. Except on probe trial tests, a flat white escape platform $(15 \mathrm{~cm} \times 15$ $\mathrm{cm})$ was used throughout all phases of training and testing. The platform was located $18 \mathrm{~cm}$ from the wall of the swimming pool, thus necessitating that the rat swim away from the swimming pool wall in order to locate the platform. For the cued water maze task described below, the platform projected $15 \mathrm{~mm}$ above the surface of the water. For all other phases of the experiment, the escape platform was submerged to a depth of $15 \mathrm{~mm}$ below the surface of the water.

\subsection{Procedures}

\subsubsection{Assessment of General Activity and Exploration}

Rodent general levels of activity were measured across two 5 min periods (one per day) in a $60.96 \mathrm{~cm} \times 60.96 \mathrm{~cm}$ chamber consisting of alternating black and 
white $10.16 \mathrm{~cm}$ squares. Activity measures included the number of squares crossed during the measurement period and the number of times the rats reared onto their hind legs. Lastly, motivational and sensorimotor deficits were assessed using a cued version of the MWM task described below.

\subsubsection{Step-Down Passive Avoidance Testing}

Step-down passive avoidance testing took place in a standard operant chamber (21-cm $\times 28-\mathrm{cm}$; Lafayette Model 84,022) with a stainless steel electrified grid floor. A $10.14-\mathrm{cm} \times 10.14 \mathrm{~cm}$ platform was located in the center of the chamber. Whenever the rat left the platform, physically touching the grid floor, a $4 \mathrm{~mA}$ current of foot shock was delivered.

\subsubsection{Water Maze Tasks}

Water maze protocols were employed to assess rodent learning and memory. For the cued place learning task, the platform was $15 \mathrm{~mm}$ above the water's surface; For the rest of the tasks, the platform was submerged to a depth of $15 \mathrm{~mm}$ below the surface of the water (the place $\&$ spatial learning set tasks). On a given trial during the spatial segments of the experiment, the rat was gently released into the pool at one of four compass points, labeled west, east, north, or south, and allowed a maximum of $60 \mathrm{sec}$ per trial to reach the escape platform. The platform location was positioned at one of four compass positions-southwest, southeast, northeast, or northwest. Escape times to the platform were recorded with a stopwatch and errors, operationally defined as crossing one of four quadrants associated with the four cardinal compass points, were recorded.

\section{1) Simple (Cued) Place Learning}

The cued place learning MWM navigation task was administered the day after step-down passive avoidance testing. Using a visible escape platform, this phase allowed for the assessment of nonassociative influences-general swimming ability, motivational deficiencies, and nondeclarative memory ability-that could influence performance during the spatial place and learning set tasks. The task included two days with 10 trials per day with the escape platform located in one of four possible locations. After successfully navigating to the platform, the rats were allowed to rest on it for about $15 \mathrm{sec}$ before the next trial.

\section{2) Spatial Water Maze Tasks}

The next two phases of the protocol were tests of spatial reference memory that varied in difficulty. The tasks involved learning the location of a submerged platform that remained constant across all trials within a given phase of the experiment. Because often only minor deficits are typically seen using the standard (high cue) version of this test [61], two variations of the task were used. A more difficult version of the place-learning task was included, as the latter version used here is considered more sensitive to spatial learning/memory impairments following adolescent drug exposure to MDMA or Foxy [28].

A more simple (high cue) version of the place-learning task lasted two days and consisted of training the rats for 10 trials per day. As earlier, the rats were 
allowed to remain on the platform for $15 \mathrm{sec}$ at the completion of each trial. Further, a test of retention was conducted through the use of a probe trial on the second day. This assessment consisted of removing the escape platform and testing the subject for a $60 \mathrm{sec}$ "free swim" not less than two hours after the last place learning trial. Time spent swimming in the target quadrant and the number of crossings over the former platform location were recorded.

The subsequent phase began the following day. A low-cue version of the place-learning task, considered to be more difficult, was accomplished through a reduction in the availability of extra-maze cues to aid navigation. The rats were trained during four consecutive trials per day Task difficulty was increased by placing a white curtain around the water maze as well as a single 60 -watt red light bulb, located beyond the curtain and below the horizon of the pool, approximately three meters from the water maze. This effectively left the rat with few visual cues to aid navigation. After successfully locating the platform, the rats were allowed to remain and rest for $15 \mathrm{sec}$. Lastly, a daily probe trial was administered not less than two hours after the last trial of the daily four-trial series.

\section{3) Spatial Learning Set}

A final phase of testing, learning set acquisition, required the animals to learn a new escape platform location daily for five consecutive days. All animals received four consecutive trials per day. Since this task requires the animal to recall its response on the immediately preceding trial, the averaged performance on Trial 2 of each day was used as an index of working (short-term) memory. As before, the rats were allowed to sit on the platform for $15 \mathrm{sec}$ at the completion of each trial.

\subsection{Assessment of Brain Dopamine and Serotonin Levels}

One week after the completion of the last behavioral testing phase of the experiment, the animals were sacrificed by cervical fracture. Immediately thereafter, the brains were removed, the hippocampus, prefrontal cortex and striatum were dissected from $1 \mathrm{~mm}$ coronal sections, frozen on dry ice and stored at $-80^{\circ} \mathrm{C}$. Subsequently, the tissue samples were homogenized in cold $0.2 \mathrm{~N}$ perchloric acid (Fisher Scientific) with the resulting homogenates centrifuged for 5 minutes at $14,000 \mathrm{rpm}$. In an analysis of biogenic amines, the supernatant was divided into aliquots for the analysis of biogenic amines dopamine and 5-HT. The aliquots of the supernatant were injected onto a C-18 reverse phase column connected to an LC amperometric detector (Bioanalytical Systems, West Lafayette, IN) fitted with a glassy carbon target electrode. The mobile phase for the separation of dopamine and 5-HT consisted of the following- $100 \mathrm{mM}$ citric acid, $75 \mathrm{mM}$ sodium phosphate, $50 \mathrm{mg} / \mathrm{l}$ disodium ethylenediamine tetraacetate, $176 \mathrm{mg} / \mathrm{l} \mathrm{oc}$ tane sulfonic acid sodium salt, $15 \%$ methanol ( $\mathrm{pH} 4.2$ ), pumped at a flow rate of $0.8 \mathrm{ml} / \mathrm{min}$. Peak height determinations were recorded with an integrator, with calculations of the quantities of dopamine and 5-HT determined on the basis of 
known standards. Statistical analysis of tissue dopamine and 5-HT concentrations were considered in units expressed in $\mathrm{ng} / \mathrm{mg}$.

\subsection{Data Analysis Plan}

For the step-down passive avoidance task, step-down latencies were analyzed for the two-day period. For all MWM tasks, escape latencies and navigation errors were the two primary measures of performance. Owning to the fact that optimal swim path distances differed depending on the various start and escape locations, the recorded escape latencies for the four start locations were normalized. Normalization was accomplished by computing the ratio of the minimum swim distance in $\mathrm{cm}$ for each of the two longer swim paths to the escape platform (e.g., a south start location and a northeast goal location) to the minimum swim of the two shorter swim paths (e.g., a north start location and a northeast goal location) trials in $\mathrm{cm}$.

Statistical analyses involved mixed analysis of variance (ANOVAs), with drug group as the between-subjects factor and days, or blocks of trials and days as within-subjects factors. In order to meet the ANOVA assumptions, the time data were transformed using the reciprocal transformation. Post-hoc analyses were performed using Tukey ${ }_{\mathrm{HSD}}$ or paired $t$-tests with a Bonferroni correction to control for multiple comparisons. A priori alpha level for acceptance was set at $p<$ 0.05 and the data analyzed using SPSS [62].

\section{Results}

\subsection{General Activity}

Assessment of the activity data revealed no group differences in the number of squares traversed or in the number of rearings during the measurement period.

\subsection{Step-Down Passive Avoidance}

The step-down passive avoidance data for each measurement period is presented in Figure 1. In the first assessment period, main effects of drug group, $F(2,18)=$ $6.50, p<0.001, \eta_{p}^{2}=0.419$, and day of testing were found, $F(1,18)=34.30, p<$ $0.001, \eta_{p}^{2}=0.656$, suggesting that stepdown latencies differed by drug group and day. Pairwise comparisons of the three groups revealed group differences in escape latency between the two drug groups and the saline-treated rats; but overall, the stepdown latencies of the two drug groups were comparable. More importantly, a significant drug group $\times$ day interaction, $F(2,18)=6.50, p<0.01$, $\eta_{p}^{2}=0.419$, was also found. Decomposition of the interaction revealed that while stepdown latencies were comparable across groups on the first day, the saline-treated rats remained on the safe platform significantly longer than either drug group. In addition, unlike the MDMA rats, the Foxy-treated animals remained on the safe platform significantly longer on day two.

With a few exceptions, the results in the second test period were similar to that in the first period. Once again, main effects of drug group, $F(1,18)=43.67$, 
$p<0.001, \eta_{p}^{2}=0.708$, and day of testing were found, $F(2,18)=5.49, p<0.025$, $\eta_{p}^{2}=0.379$, but post hoc examination of the drug group means indicated that only the MDMA latencies differed from those of the saline-treated rats. Finally, the drug group $\times$ day interaction was significant, $F(2,18)=5.60, p<0.025, \eta_{p}^{2}$ $=0.379$. Post hoc examination of the means (see Figure 1, Period 2) revealed that the saline- and Foxy-treated rats remained on the safe platform significantly longer on trial 2 than on trial 1, while stepdown latencies across trials were comparable in the MDMA-treated rats.

When the animals were assessed for the $3^{\text {rd }}$ period, as before, the main effects of days, $F(1,18)=186.19, p<0.001, \eta_{p}^{2}=0.912$, and drug groups, $F(2,18)=$ $17.56, p<0.001, \eta_{p}^{2}=0.661$, as well as drug group $\mathrm{X}$ days interaction, $F(2,18)$ $=20.80, p<0.001, \eta_{p}^{2}=0.698$, were all significant. Simply, stepdown latencies were longer on day 2 and stepdown latencies of the MDMA-treated rats were significantly different from that of both the Foxy- and saline-treated animals, with the latter two not significantly different. However, unlike at earlier assessment periods, all three groups remained on the escape platform significantly longer on day 2, although, as suggested by the interaction, escape latencies on this day were significantly longer for the saline- and Foxy-treated animals than rats in the MDMA group (see Figure 1, Period 3).

It should be noted that three rats, one from each group had died during the period between the $3^{\text {rd }}$ and $4^{\text {th }}$ assessment periods. As is evidenced by the group and drug group $\times$ days interaction, both nonsignificant, no drug associated effects were found at the fourth measurement point. Only the main effect of days was significant, with stepdown latencies consistently longer on day 2 for all groups, $F(1,15)=228.24, p<0.001, \eta_{p}^{2}=0.927$.

\subsection{Cued Place Learning}

For the cued place learning data, the escape latencies were analyzed using 3 (drug groups) $\times 2$ (blocks of trials) $\times$ days (of testing) mixed ANOVAs, with the latter two factors as within-subjects effects. An examination of Period 1 revealed a main effect of blocks, $F(1,18)=34.72, p<0.001, \eta_{p}^{2}=0.659$, with latencies improving by the second block of training. Similarly, the main effect of days was

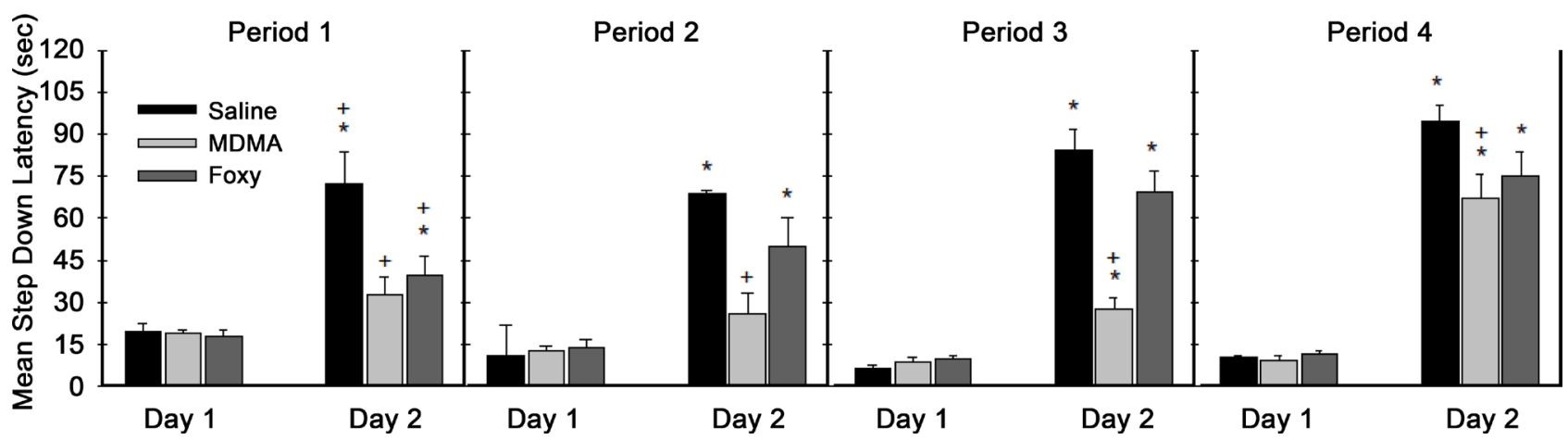

Figure 1. Step-down passive avoidance learning for the MDMA, Foxy, an control groups. ${ }^{\star}$ significant change $(p<0.05)$ in stepdown latency on day 2. +significantly different latency from that of the control group $(p<0.05)$. 
significant, $F(1,18)=51.23, p<0.001, \eta_{p}^{2}=0.740$, as was the drug group $\mathrm{X}$ days, $F(2,18)=11.57, p<0.01, \eta_{p}^{2}=0.562$. The remaining interactions were nonsignificant. Closer examination of the group $\mathrm{X}$ days interaction revealed that latencies between the saline- and Foxy-treated rats differed on day two of the first assessment period.

By the $2^{\text {nd }}$ assessment period, all differences among the three groups and evidenced by the lack of either a drug main effect or interaction (i.e., all $p s>0.05$ ). As the main effect of blocks, smallest $F(1,15)=12.97, p<0.01, \eta_{p}^{2}=0.464$, and days, smallest $F(1,15)=17.96, p<0.001, \eta_{p}^{2}=0.545$, suggested, the animals generally performed better on latter trials and days of training.

\subsection{Easy Place Learning}

When the easy place learning data were considered, drug effects, if any, resolved over assessment periods. During the first phase of testing, only the main effects of days, $F(1,18)=19.59, p<0.001, \eta_{p}^{2}=0.521$, and blocks, $F(1,18)=27.22, p$ $<0.001, \eta_{p}^{2}=0.602$ were significant, each suggestive of improvements as a function of the number of trials. However, assessment of the probe trial data revealed a significant drug effect, $F(2,18)=10.28, p<0.01, \eta_{p}^{2}=0.533$. Subsequent Tukey $_{\mathrm{HSD}}$ tests revealed that the saline rats spent significantly more time in the target quadrant $(M=33.15 \mathrm{sec})$ than either of the drug groups both of which spent similar amounts of time in the target quadrant $(M s=21.99$, Foxy \& 22.59, MDMA).

Reviewing the $2^{\text {nd }}$ assessment phase, with the exception of a significant effect of drug group, $F(2,18)=14.38, p<0.001, \eta_{p}^{2}=0.615$, no additional main effects or interactions were found. Interestingly, consideration of the main effect revealed that escape times were significantly higher in the Foxy group $(M=3.91$ sec) than in the MDMA and saline groups. Here, the escape times of the latter two groups were comparable $(M s=2.82 \& 2.68)$. Nonetheless, probe trial assessment of time spent in the target quadrant differed by drug group, $F(2,18)=$ 27.64, $p<0.001, \eta_{p}^{2}=0.754$ and, once again, Tukey ${ }_{\mathrm{HSD}}$ tests revealed that the saline rats spent significantly longer in former escape platform quadrant ( $M=$ 38.01) than either drug group ( $M s=24.21 \& 21.26$, MDMA \& Foxy).

By the $3^{\text {rd }}$ assessment period, all group differences associated with either main effects or interactions were absent. In addition, as evidenced by similar times spent in the target quadrant, probe trial performances were comparable. This pattern persisted in the $4^{\text {th }}$ assessment period as well.

\subsection{Hard Place Learning}

Data from the four hard place learning assessment periods are presented in Figure 2. For the hard place learning data, the escape latencies were analyzed using 3 (drug groups) $\times 5$ days (of testing) mixed ANOVAs. An examination of the data from the first assessment period revealed little of interest. Only the main effect of days was significant, $F(4,72)=9.22, p<0.001, \eta_{p}^{2}=0.339$, suggesting 


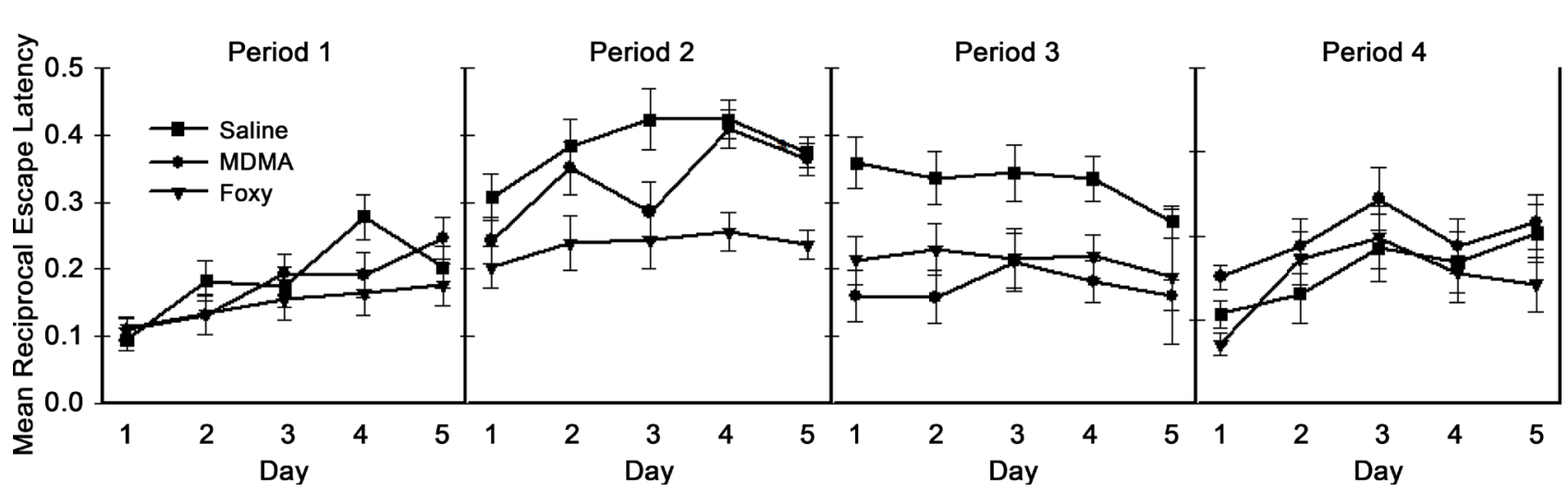

Figure 2. Hard place learning results. The data reflects escape performance over the 5 test days for each assessment period. Vertical bars represent the standard error of the mean.

an improvement in escape latencies across the assessment period. In addition, escape latencies were comparable on the probe trials.

A drug-related divergence in performance began to emerge in the $2^{\text {nd }}$ assessment period. Here, the main effect of days was significant, $F(4,72)=7.80, p<$ $0.001, \eta_{p}^{2}=0.302$, as was the main effect of drug group, $F(2,18)=7.58, p<$ $0.01, \eta_{p}^{2}=0.457$. As seen in Figure 2, Period 2, performance generally improved across the early test days and then stabilized by the fourth test day. More importantly, as seen in Figure 2, Period 2, the performance of the saline-treated rats $(M=0.382)$ was superior to that of both drug groups while performance of the drug-treated rats was comparable $(M s=0.331 \& 0.236$, MDMA \& Foxy, respectively). Last, assessment of the probe trial data revealed a significant drug effect as well, $F(2,18)=10.67, p<0.01, \quad \eta_{p}^{2}=0.543$. Subsequent Tukey ${ }_{\mathrm{HSD}}$ tests revealed that the saline rats spent significantly more time in the target quadrant $(M=0.026)$ than either of the drug groups, both of which spent similar amounts of time in the target quadrant $(M s=0.052 \& 0.047$, MDMA \& Foxy-treat rats, respectively).

As seen in Figure 2, Period 3, the patterns of group performance largely continued. Although the main effect of days was nonsignificant, a main effect of drug group was found, $F(2,15)=10.67, p<0.01, \eta_{p}^{2}=0.477$. Once again, the performance of saline-treat rats $(M=0.263)$ was superior to that of both MDMA $(M=0.140)$ and Foxy-treated rats $(M=0.171)$. Similarly, assessment of the probe trial data revealed a significant drug effect, $F(2,15)=5.72, p<0.05, \quad \eta_{p}^{2}=$ 0.389 , with the saline-treated rats spending significantly more time in the target quadrant $(M=0.031)$ than the MDMA- $(M=0.061)$ but not the Foxy-treated $(M=0.046)$ rats.

Although drug effects were detected in the $2^{\text {nd }}$ and $3^{\text {rd }}$ assessment periods, no drug associated effects were found in the $4^{\text {th }}$ assessment period and only the main effect of days was significant, $F(4,56)=5.76, p<0.01, \quad \eta_{p}^{2}=0.291$, (see Figure 2, period 4). In addition, examination of the probe trial data revealed that the time spent in the target quadrant was comparable across all groups. 


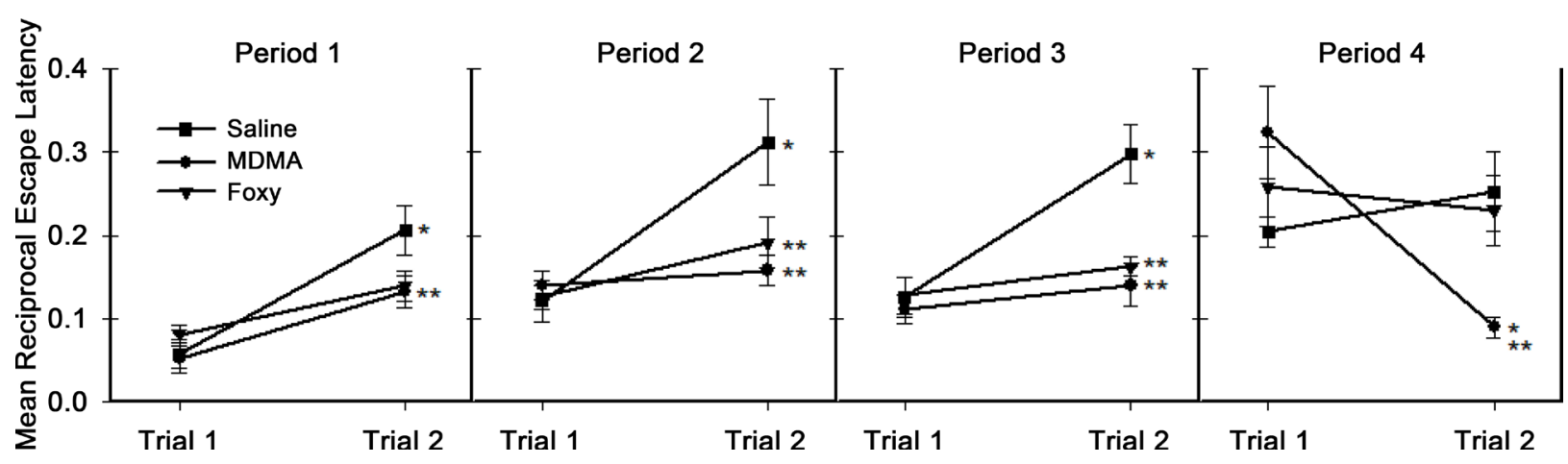

Figure 3. Graphical representation of the spatial learning set task for the four assessment periods. The data represent the performance on trial one versus trial two collapsed across the 5-day test period. ${ }^{*}$ Significant difference between trial one and trial two escape latencies $(p<0.05) .{ }^{*}$ Significantly different from saline rats $(p<0.05)$. Vertical bars represent the standard error of the mean.

\subsection{Spatial Learning Set}

The results associated with the four assessment periods of Learning set performance are presented in Figure 3. Here, the data were analyzed using 3 (drug groups) $\times 2$ trials ( 1 vs. 2 ) mixed ANOVAs, with trials as a within-subjects effect.

Considering the $1^{\text {st }}$ assessment period, although the main effect of drug group was nonsignificant, a main effect of trials, $F(1,18)=56.15, p<0.001, \eta_{p}^{2}=$ 0.757 , and a group $\mathrm{X}$ trials interaction, $F(2,18)=4.50, p<0.05, \eta_{p}^{2}=0.333$, were found. Thus, the rats typically found the platform more quickly on trial 2 than trial 1; but when considered within each trial, escape latencies differed across the groups. Post hoc examination of the groups revealed that on trial 2, the saline-treated rats found the platform significantly faster than the MDMAbut not the Foxy-treated rats.

The second assessment period revealed a somewhat similar pattern to that of the first assessment. While the main effect of drug group was nonsignificant, a main effect of trials was found, $F(1,18)=18.94, p<0.001, \eta_{p}^{2}=0.513$. More important, the group $\mathrm{X}$ trials interaction remained significant during this assessment phase, $F(2,18)=6.00, p<0.025, \eta_{p}^{2}=0.400$. Subsequent Tukey нsD $_{\text {D }}$ tests revealed that the saline-treated rats located the platform faster on trial 2 than on trial 1 . The performance of these animals was superior to that of the two drug-treated groups on this trial, whereas the trial 2 performances were comparable (see Figure 3). However, the Foxy rats also found the escape platform more quickly on trial 2 than on trial 1.

Consideration of the $3^{\text {rd }}$ assessment period data revealed the following: Main effects of both drug groups, $F(1,18)=5.80, \mathrm{p}<0.025, \eta_{p}^{2}=0.392$, and trials, $F(1,18)=23.01, p<0.001, \eta_{p}^{2}=0.561$, were found. Here, escape latencies among the saline-treated rats were superior to the drug-treated rats; but the latter two did not differ, and escape latencies where faster on trial 2. As before, the group $\times$ trials interaction was significant, $F(2,18)=8.30, p<0.01, \eta_{p}^{2}=0.480$. Decomposition of the interaction revealed that only the saline-treated rats found 
the escape platform faster on trial 2 than on trial 1. In addition, the trial 2 performance of the saline -treated rats was superior to that of both drug groups with the latter two again performing similarly.

By the $4^{\text {th }}$ assessment period, a different pattern emerged (see Figure 3, Period 4). Here, although at first glance the escape latencies appeared different across trials, neither main effects were significant. However, a drug group $\mathrm{X}$ trials interaction was found, $F(2,15)=6.27, p<0.025, \eta_{p}^{2}=0.455$. Decomposition of the interaction revealed the following: The escape latencies of the MDMA-treated rats were significantly higher on trial 2 than on trial 1, while no trial 1 vs. trial 2 differences were observed among rats in the other two groups. Thus, MDMAtreated rats were impaired when the expected platform location was changed on trial 2. This observation is further supported by between-group comparisons of trial 2 performance. Here, MDMA group latencies were significantly higher than those of both the saline- and Foxy-treated rats, neither of which differed from the other. Here, the latter two groups did appear to be impaired as a result of the trial 2 shift in platform location (see Period 4).

\subsection{Assessment of Brain Dopamine and Serotonin Levels}

Examination of cortical or subcortical dopamine and serotonin levels revealed no significant differences between the saline and two drug groups or between the MDMA and Foxy-treated animals (all $p s>0.05$ ).

\section{Discussion}

While cost-effective, cross-sectional research designs comparing animals of different ages are limited by the possibility of flawed conclusions about changes that occur across time [60]. Often such limitations are discussed in context of research on age-related changes in memory performance [63]. On the other hand, longitudinal designs permit the examination of changes in memory function across a definable period of time, allowing for the examination of time-related change as well as physiological and neural changes [64] [65]. Thus, investigations employing rodent animal models for longitudinal assessment are valuable when examining the long-term effects following exposure to potentially neurotoxic compounds. Additionally, longitudinal research designs permit the empirical examination of pertinent research questions in time frames that are not feasible using longitudinal studies with human adolescents (see [52] for review). Here, we were able to assess two such compounds, MDMA and Foxy, using an animal model with a significantly shorter lifespan than that of humans.

One unexpected result of the present experiment, was the persistent difference in day two stepdown latencies between the saline and MDMA-treated animals. While an improvement in the day two performance of the MDMA-treated animals was seen across assessment periods, the saline-treated animals remained on the platform significantly longer than the MDMA-treated rats. While speculative, a number of reports have implicated MDMA in long-term impairments to 
cognition, including cognitive impulsivity [11] [27] [33] [37].

Mammalian adolescence is a period marked by widespread maturational changes in the brain [21]. In humans, neurocognitive assessments clearly suggest that adolescent development consistently is associated with marked and continued improvement in both information processing speed and tasks that are associated with executive function. Collectively, these tasks measure key executive domains including attention, working memory, decision-making, and inhibition of maladaptive responses [1]. Indeed, development continues throughout adolescence with full maturation of prefrontal and associated cortices not occurring until early adulthood [1] [66] [67]. Further, a number of maturational changes during adolescence to 5-HT brain systems have been elucidated [68] [69]. Differential expression of 5-HT receptors with age has also been reported [70]. As a consequence, the period of mammalian adolescent brain development is one marked by susceptibility to the neurotoxic effects of compounds such as MDMA or Foxy [3] [6] [7] [71]. Further, since it can alter dopaminergic activity [7] [72], adolescent exposure to drugs such as MDMA may well render the brain more vulnerable to subsequent noxious chemical exposure well after the exposure period of this compound [3]. Foxy may well produce a similar vulnerability, albeit with a smaller effect. At any rate, there is evidence that MDMA can induce a variety of neuroinflammatory responses in a number of brain regions [3]. For example, adolescent exposure of MDMA is capable of inducing an increase in astroglia [73] as well as increasing both interleukin-1 $\beta$ (IL- $1 \beta$ ) and the IL- $1 \beta$ precursor protein (pro-IL-1 $\beta$ ) in the rat frontal cortex and hypothalamus [74].

When different time points in adolescent development are considered, there is convincing evidence that both neurotoxic and neurobehavioral changes normally associated with MDMA exposure are dependent on the age of exposure [75]. In addition, reductions in hippocampal, striatum, and cortical 5-HT levels 60 days following the final MDMA exposure have been reported [76], a result that was consistent with other research [27]. Certainly, variables such as frequency and duration of drug exposure are important when considering the neurochemical effects associated with MDMA use [45] [77]. Indeed, there is considerable evidence that exposure to a variety of compounds during childhood may contribute to some neurodegenerative diseases processes in the adulthood [78]. For example, a number of neurodevelopmental processes, such as increases in neural connections and myelination, occur across periods lasting from pre-natal development through late adolescence and early adulthood [79]. Given this, exposure to exogenous compounds during these periods could indeed adversely impact brain development. Yet, such consequences to exposure may not be seen until much later in the lifespan. The putative neurotoxic effects of MDMA include oxidative stress and oxidative stress and both are commonly associated with neurodegenerative disease processes [80] [81]. For example, in one recent report exploring such links, adolescent exposure to MDMA in APP/PS1 mice was associated with a concomitant increase in $\mathrm{A} \beta$ plaques in the striatum in early adult- 
hood [79].

Including the present investigation, when compared to MDMA, less data is available that is concerned with the specific effects and possible health costs associated with the use of the drug Foxy. Certainly, previous reports about the consequences associated with its use by humans [82] [83] and toxicological investigations [84] [85] [86] were a cause for concern. While relatively few in number, the reports using animal models to explore the central nervous system effects [24] [25] [26] [27] [87] [88] and sexual dimorphic effects [28] established a need to continue to examine the short- and long-term effects of this drug.

While there is support for the contention that adolescent Foxy exposure is capable of producing long-term cognitive changes [26], the effects, when compared to MDMA observed in the present study, are smaller and dissociable from the effects of MDMA [24] [28]. Skelton and colleagues suggested that the observed differences in the behavioral effects associated with each drug is a reflection that MDMA and Foxy are not equipotent and/or do not exert the same level of CNS effects [24]. On the basis of the present study, this appears to have some validity. Nonetheless, future research is warranted, especially as behavioral deficits were found, presumably long after any definitive alterations in 5-HT levels were detected. Indeed, the MDMA and, to a lesser extent, Foxy effects seem to persist for a substantial period following abstinence.

One major finding of our study was a lack of group differences on any of our neurochemical measures. First, the drug effects do differ across species. In mice, MDMA has relatively selective neurotoxic effects on dopamine, while 5-HT concentrations are largely spared. Conversely, 5-HT neurotoxicity is commonly reported in studies employing the use of nonhuman primates or rats [89]. Past research has indicated that, depending on protocol and dose, MDMA is capable of inducing a reduction in 5-HT tissue concentration for up to 52 weeks postexposure [90] [91] (see also, [92]). However, other investigations reported transient 5-HT deficits with recovery within several months [92] [93] [94] [95]. The bulk of the reported research appears to support the supposition that MDMA is capable of producing both alterations in the structure of 5-HT terminals as well as changes in a number of biochemical markers [96]. Conversely, direct evidence of MDMA-related damage to the soma of 5-HT neurons is largely absent [96]. As evidence of 5-HT neurotoxicity, this latter observation led to the supposition that MDMA is capable of producing a distal axotomy of 5-HT neurons [97] [98]. Generally, there is strong support for this from immunohistological studies reporting a profound loss of fine serotonergic axon terminals throughout the forebrain [99] [100].

Consideration of a human longitudinal study [101] is instructive for the consideration of the findings reported here and elsewhere. In the study, assessment of abstinent MDMA users' memory performance suggested a continued impairment, with no sign of improvement in tests of verbal memory even after over two and a half years of abstinence. Following reduced use of MDMA, SERT 
availability approached that of normal levels and normal SERT availability was observed among ex-users - a finding consistent with that of others [102] [103].

In addition, although further research needs to be done, the age of drug exposure is instructive. Following MDMA exposure to rats from PNDs 35 to 60, Piper and Meyer [67] observed a deficit in non-spatial working memory, even with a mild reduction in 5-HT binding measured on PND 70. Further, the timing of exposure appears to be critical [45]. Klomp and colleagues found that, while MDMA exposure produced significant reductions in 5-HTT binding in areas of the brain, the reductions where considerably smaller in adolescent rats when compared to adult rats [49]. Further, the reported reductions were not consistent across all measured areas of the brain since the effect associated with the age of exposure was observed in the frontal cortex but not in the midbrain. Here, the effect is probably a result of the different points in brain development and maturation of the midbrain in rats [45]. While MDMA-induced 5-HT neurotoxicity varies depending on the age of exposure, from largely absent during gestation to large effects in adulthood, decreased 5-HT or metabolite levels are observed following adolescent exposure and compromised cognitive function can be observed in the absence of discernable damage to 5-HT brain systems [42].

In addition, García-Cabrerizo and García-Fuster reported that MDMA effects produce impairments of the GABAergic system and neurofilament proteins, at least in the hippocampus [104]. In this study, the effects were observed independently of the stage of development-adolescent or young adult. Such effects are in addition to the MDMA-associated degeneration of 5-HT terminals in multiple brain regions, including the cortex and hippocampus observed in both experimental animal models and research with humans [5] [12] [77] [105]. In a review of the literature, Teixeira-Gomes and colleagues [45] found substantial evidence of monoaminergic neurotoxicity associated with stimulants including MDMA exposure (see also, [106]). As noted earlier, MDMA is capable of producing marked reductions in 5-HT levels [107] [108] [109] [110] including the induction of degenerative processes to nerve terminals [109] [111], and neuronal cell death in widespread areas of the brain [112] [113] [114]. Lastly, MDMA stimulates acetylcholine release, although this reported effect appears to be minor in comparison to its effects on 5-HT and dopaminergic receptors [115].

Collectively, the MDMA studies clearly point to learning and memory deficits, with many of the deficits reflective of problems in higher level cognition [15]. Recently, it has been proposed that some of the memory impairments associated with MDMA could result from inhibition of hippocampal neurogenesis [104] during adolescent MDMA exposure [116]. As Nyberg [15] noted, a number of cognitive processes-contextual memory, spatial memory, and working memory-are directly regulated or influenced by adult hippocampal neurogenesis (see also, [117]). Additional factors that separately or collectively in complex ways may drive the cognitive effects reported here and elsewhere include alterations 
in metabolic processes [118] [119], oxidative stress [120] [121], and inflammation [122].

To reiterate, much less is known about the effects of Foxy [26]. Foxy has effects on 5-HT systems in the brain, acting on the 5-HT2A receptor [123] as a SERT inhibitor [124]. An increase in corticosterone is associated with MDMA exposure in neonatal [125], young [126], and adult rats [127] [128]. Foxy, too, seems to increase corticosterone levels in preweaned and in adult rats [129] [130] but not if introduced during adolescence [129]. Such findings have implications for assessments of cognitive performance since alterations in cortisone and glucose levels can modulate memory [131].

Among the crucial variables that appear to drive the physiological effects associated these compounds, the dose of these compounds is a key consideration. While a discussion of this issue is beyond the scope of the present report, one investigation is illustrative. In this study, the effects of daily exposure of MDMA for four days over PNDs 38 to 41 were examined. An MDMA dose of $5 \mathrm{mg} / \mathrm{kg}$ had no effect on behavioral measures (e.g., anxiety, place conditioning) while a dose of $10 \mathrm{mg} / \mathrm{kg}$ dose produced a number of effects [5]. Further, the monoaminergic parameters were only affected at the $10 \mathrm{mg} / \mathrm{kg}$ dose and thus congruent with the behavioral effects. Last, 5-HT hippocampal levels were unchanged following the higher MDMA exposure but were reduced in the amygdala.

While issues associated with interspecies scaling are a concern [132] [133], research using nonhuman primates strongly indicated that MDMA caused cortical 5-HT neuron damage [134] [135], with a marked reduction in 5-HT axons observed seven years after exposure [134]. Similarly, a decrease in 5-HT synthesis in the frontal cortex has been observed in humans who have abused MDMA [136]. However, as noted earlier, owing to the methodological issues associated with MDMA research with human subjects, such reports should be considered with caution.

In summary, when considered alongside of previous research [24] [27] [28] [88] [125] [126] [130], our results indicate that MDMA and 5-MeO-DIPT cause acute but not lasting changes in 5-HT tissue concentrations. In particular, MDMA appears to contribute to a long-term cognitive impairment, even in the absence of lower measured 5-HT. When the literature is collectively considered, mainly 5-HT systems have been studied, although dopaminergic processes have been explored [45]. Indeed, this is especially true for MDMA, even with its considerable literature. What clearly is needed, is an array of research activities that more broadly examine MDMA-induced neurotoxicity are needed [45]. Similarly, research consideration should apply to Foxy as well.

\section{Limitations}

Although the use of a longitudinal design in our study allowed for the examination of the long-term consequences of MDMA or Foxy following exposure in adolescence, there are still limitations that should be mentioned. First, the origi- 
nal sample size was less than optimal for a study lasting more than a year. Certainly, the loss of one animal in each group was a foreseeable yet undesirable consequence. Thus, the statistical power of the present study is limited. An additional limitation of the present study was the use only male rats. There continues to be concerns raised when including female animals such as an increase in data variability [137] usually justified by concerns of hormonal fluctuation in the female estrus cycle [138]. Given that such concerns are not necessarily supported by the evidence [138], the current guidelines of the National Institutes of Health encourage consideration of both sexes [139]. As such, the results here should be considered in light of this limitation, especially since sex differences in the effects of MDMA have been reported [28] [140] [141] [142] [143]. An additional consideration is concerned with the housing of the subjects. Although standard stainless-steel rodent cages are still widely used, social housing is recommended [60]. While all three groups were housed and maintained under identical conditions, there is evidence that individual housing is stressful to rodents triggering behavioral and physiological changes [144] [145]. Last, it might be of interest to conduct a longitudinal examination of Greek cross response learning performance as both MDMA and Foxy appear to adversely affect performance on this task [25] [26] [27].

\section{Acknowledgements}

The present research was sponsored in part by a grant from the Palm Beach Atlantic University Faculty Research Committee to David M. Compton. The authors would like to thank L. Lander for her assistance with the collection of data and data entry and N. Hernandez for their assistance with the HPLC assessment of 5-HT and dopamine.

\section{References}

[1] Spear, L.P. (2011) Brain Development. In: Brown, B.B. and Prinstein, M.J., Eds., Encyclopedia of Adolescence, Volume 1, Academic Press, New York, 87-96.

[2] Tymula A., Rosenberg Belmaker, L.A., Roy, A.K., Ruderman, L., Manson, K., Glimcher, P.W. and Levy, I. (2012) Adolescents' Risk-Taking Behavior Is Driven by Tolerance to Ambiguity. Proceedings of the National Academy of Sciences, 109, 17135-17140. https://doi.org/10.1073/pnas.1207144109

[3] Costa, G., Simola, N. and Morelli, M. (2014) MDMA Administration During Adolescence Exacerbates MPTP-Induced Cognitive Impairment and Neuroinflammation in the Hippocampus and Prefrontal Cortex. Psychopharmacology, 231, 40074018. https://doi.org/10.1007/s00213-014-3536-Z

[4] Capela, J.P., Carmo, H., Remião, F., Bastos, M.L., Meisel, A. and Carvalho, F. (2009) Molecular and Cellular Mechanisms of Ecstasy-Induced Neurotoxicity: An Overview. Molecular Neurobiology, 39, 210-271. https://doi.org/10.1007/s12035-009-8064-1

[5] Cox, B.M., Shah, M.S., Cichona, T., Tancer, M.E., Galloway, M.P., Thomas, D.M. and Perrine, S.H. (2014) Behavioral and Neurochemical Effects of Repeated MDMA Administration during Late Adolescence in the Rat. Progress in Neu- 
ro-Psychopharmacology and Biological Psychiatry, 48, 229-235.

[6] Daza-Losada, M., Rodríguez-Arias, M., Aguilar, M.A. and Miñarro, J. (2009) Acquisition and Reinstatement of MDMA-Induced Conditioned Place Preference in Mice Pre-Treated with MDMA or Cocaine during Adolescence. Addiction Biology, 14, 447-456. https://doi.org/10.1111/j.1369-1600.2009.00173.x

[7] Spear, L.P. (2000) The Adolescent Brain and Age-Related Behavioral Manifestations. Neuroscience and Biobehavioral Reviews, 24, 417-463.

[8] Peroutka, S.J., Newman, H. and Harris, H. (1988) Subjective Effects of 3,4-Methylenedioxymethamphetamine in Recreational Users. Neuropharmacology, 1, 273-277.

[9] Morgan, M.J. (2000) Ecstasy (MDMA): A Review of its Possible Persistent Psychological Effects. Psychopharmacology, 152, 230-248. https://doi.org/10.1007/s002130000545

[10] Bedi, G., Hyman, D. and de Wit, H. (2010) Is Ecstasy an Empathogen? Effects of MDMA on Prosocial Feelings and Identification of Emotional States in Others. Biological Psychiatry, 68, 1134-1140.

[11] Kalechstein, A.D., De La Garza, R. II, Mahoney, J.J. III, Fantegrossi, W.E. and Newton, T.F. (2007) MDMA Use and Neurocognition: A Meta-Analytic Review. Psychopharmacology, 189, 531-537. https://doi.org/10.1007/s00213-006-0601-2

[12] Parrott, A.C. (2015) Why All Stimulant Drugs Are Damaging to Recreational Users: An Empirical Overview and Psychobiological Explanation. Human Psychopharmacology: Clinical and Experimental, 30, 213-224. https://doi.org/10.1002/hup.2468

[13] Rogers, G., Elston, J., Garside, R., Roome, C., Taylor, R., Younger, P., Zawada, A. and Somerville, M. (2009) The Harmful Health Effects of Recreational Ecstasy: A Systematic Review of Observational Evidence. Health Technology Assessment, 13, i-315.

[14] Turillazzi, E., Riezzo, I., Neri, M., Bello, S. and Fineschi, V. (2010) MDMA Toxicity and Pathological Consequences: A Review about Experimental Data and Autopsy Findings. Current Pharmaceutical Biotechnology, 11, 500-509. https://doi.org/10.2174/138920110791591481

[15] Nyberg, F. (2014) Structural Plasticity of the Brain to Psychostimulant Use. Neuropsychopharmacology, 87, 115-124.

[16] Molero-Chamizo, A. (2005) 3,4-Methylenedioxymethamphetamine ("Ecstasy"): Its Long-Term Emotional and Cognitive Effects, and Serotonin Depletion. Revista de Neurologia, 41, 108-114.

[17] Halpin, L.E., Collins, S.A. and Yamamoto, B.K. (2014) Neurotoxicity of Methamphetamine and 3,4-Methylenedioxymethamphetamine. Life Sciences, 97, 37-44.

[18] Eichenbaum, H. (2008) Introduction and Overview. In: Menzel, R. and Byrne, J.H., Eds., Learning and Memory: A Comprehensive Resource, Volume 3, Memory Systems, Elsevier, New York, 1-141.

[19] Jiang, X.-L., Shen, H.-W. and Yu, A.-M. (2015) Potentiation of 5-MethoxyN,N-Dimethyltryptamine-Induced Hyperthermia by Harmaline and the Involvement of Activation of 5-HT1A and 5-HT2A Receptors. Neuropharmacology, 89, 342-351.

[20] Yu, A.-M. (2008) Indolealkylamines: Biotransformations and Potential Drug-Drug Interactions. AAPS Journal, 10, 242-253. https://doi.org/10.1208/s12248-008-9028-5

[21] Carlson, N.R. (2017). Physiology of Behavior. 12th Edition, Pearson, Upper Saddle River.

[22] Carod-Artal, F.J. (2015) Alucinógenos en las Culturas Precolombinas Mesoameri- 
canas. Neurologia, 30, 42-49.

[23] Shulgrin, A. and Carter, M.F. (1980) N,N-Diisopropyltryptamine (DIPT) and 5-Methoxy-N,N-Diisopropyltryptamine (5-MeODIPT). Two Orally Active Tryptamine Analogs with CNS Activity. Communications in Psychopharmacology, 4, 363-369.

[24] Skelton, M.R., Schaefer, T.L., Herring, N.R., Grace, C.E., Vorhees, C.V. and Williams, M.T. (2009) Comparison of the Developmental Effects of 5-Methoxy-N, N-Diisopropyltryptamine (Foxy) to (+)-3,4-Methylenedisoxymethamphetamine (Ecstasy) in Rats. Psychopharmacology, 204, 287-297. https://doi.org/10.1007/s00213-009-1459-x

[25] Compton, D.M., Selinger, M.C., Testa, E.K. and Larkins, K.D. (2006) An Examination of the Effects of 5-Methoxy-N,N-Diisopropyltryptamine Hydrochloride (Foxy) on Cognitive Development in Rats. Psychological Reports, 98, 651-661.

https://doi.org/10.2466/pr0.98.3.651-661

[26] Compton, D.M., Dietrich, K.L., Selinger, M.C. and Testa, E.K. (2011) 5-Methoxy-N, $\mathrm{N}$-di(iso)propyltryptamine Hydrochloride (Foxy)-Induced Cognitive Deficits in Rat after Exposure in Adolescence. Physiology and Behavior, 103, 203-209.

[27] Compton, D.M., Selinger, M.C., Westman, E. and Otero, P. (2011) Differentiation of MDMA or 5-MeO-DIPT Induced Cognitive Deficits in Rat Following Adolescent Exposure. Psychology and Neuroscience, 9, 105-124. https://doi.org/10.1037/pne0000043

[28] Compton, D.M., Luetzenberg, F.S. and Watkins, E. (2016) Tripping the Light Fantastic: Modelling the Consequences of Recreational Use of MDMA or 5-Meo-Dipt In Humans Using Weekend "Rave" Exposures in Rat. Psychology and Neuroscience, 9, 157-169. https://doi.org/10.1037/pne0000043

[29] Pettenuzzo, L.F., Wyse, A.T.S., Wannamacher, C.M.D., Dutra-Filho, C.S., Netto, C.A. and Wajner, M. (2003) Evaluation of Chronic Administration of Drugs on Rat Behavior in the Water Maze. Brain Research Protocols, 12, 109-115.

[30] Wagner, D., Becker, B., Koester, P., Gouzoulis-Mayfrank, E. and Daumann, J. (2013) A Prospective Study of Learning, Memory, and Executive Function in New MDMA Users. Addiction, 108, 136-145. https://doi.org/10.1111/j.1360-0443.2012.03977.x

[31] Hadjiefthyvoulou, F., Fisk, J.E., Montgomery, C. and Bridges, N. (2011) Everyday and Prospective Memory Deficits in Ecstasy/Polydrug Users. Journal of Psychopharmacology, 25, 453-464. https://doi.org/10.1177/0269881109359101

[32] Hadjiefthyvoulou, F., Fisk, J.E., Montgomery, C. and Bridges, N. (2011) Prospective Memory Functioning among Ecstasy/Polydrug Users: Evidence from the Cambridge Prospective Memory Test (CAMPROMPT). Psychopharmacology, 215, 761-774. https://doi.org/10.1007/s00213-011-2174-y

[33] Gouzoulis-Mayfrank, E. and Daumann, J. (2009) Neurotoxicity of Drugs of Abuse-The Case of Methylenedioxyamphetamines (MDMA, Ecstasy), and Amphetamines. Dialogues in Clinical Neuroscience, 11, 305-317.

[34] Laws, K.R. and Kokkalis, J. (2007) Ecstasy (MDMA) and Memory Function: A Meta-Analytic Update. Human Psychopharmacology: Clinical \& Experimental, 22, 381-388. https://doi.org/10.1002/hup.857

[35] Nulsen, C.E., Fox, A.M. and Hammond, G.R. (2010) Differential Effects of Ecstasy on Short-Term and Working Memory: A Meta-Analysis. Neuropsychology Review, 20, 21-32. https://doi.org/10.1007/s11065-009-9124-z

[36] Zakzanis, K.K. and Campbell, Z. (2006) Memory Impairment in Now Abstinent 
MDMA Users and Continued Users: A Longitudinal Follow-Up. Neurology, 66, 740-741. https://doi.org/10.1212/01.wnl.0000200957.97779.ea

[37] Zakzanis, K.K., Campbell, Z. and Jovanovski, D. (2007) The Neuropsychology of Ecstasy (MDMA) Use: A Quantitative Review. Human Psychopharmacology: Clinical \& Experimental, 22, 427-435. https://doi.org/10.1002/hup.873

[38] Croft, R.J., Mackay, A.J., Mills, A.T. and Gruzelier, J.G. (2001) The Relative Contributions of Ecstasy and Cannabis to Cognitive Impairment. Psychopharmacology, 153, 373-379. https://doi.org/10.1007/s002130000591

[39] Dafters, R.I., Hoski, R. and Talbot, A.C. (2004) Contribution of Cannabis and MDMA "Ecstasy" to Cognitive Changes in Long-Term Polydrug Users. Psychopharmacology, 173, 405-410. https://doi.org/10.1007/s00213-003-1561-4

[40] De Sola, L., Lopis, S., Miguelez-Pan, M., Peña-Casanova, J., Poudevida, S., Farré, M., Pacifici, R., Böhm, P., Abanades, S., Verdejo García, A., Langohr, K., Zuccaro, P. and de la Torre, R. (2008) Cognitive Performance in Recreational Ecstasy Polydrug Users: A Two-Year Follow-Up Study. Journal of Psychopharmacology, 22, 498-510. https://doi.org/10.1177/0269881107081545

[41] Daumann, J., Fischermann, T., Heekeren, K., Henke, K., Thron, A. and Gouzoulis-Mayfrank, E. (2005) Memory-Related Hippocampal Dysfunction in Poly-Drug Ecstasy (3,4-Methylenedioxymethamphetamine) Users. Psychopharmacology, 180, 607-611. https://doi.org/10.1007/s00213-004-2002-8

[42] United States Department of Health and Human Services (2009) Protection of Human Subjects, 45 C.F.R. 46.

https://www.hhs.gov/ohrp/regulations-and-policy/regulations/45-cfr-46/index.html

[43] Hawkey, A., April, L.B. and Galzio, M. (2014) Effects of MDMA on Olfactory Memory and Reversal Learning in Rats. Neurobiology of Learning and Memory, 114, 209-216.

[44] Tirelli, E., Laviola, G. and Adriani, W. (2003) Ontogenesis of Behavioral Sensitization and Conditioned Place Preference in Laboratory Rodents. Neuroscience and Biobehavioral Reviews, 27, 163-178.

[45] Teixeira-Gomes, A., Costa, V.M., Feio-Azevedo, R., de Lourdes Bastos, M., Carvalho, F. and Capela, J.P. (2015) The Neurotoxicity of Amphetamines during the Adolescent Period. International Journal of Developmental Neuroscience, 41, 44-62.

[46] Broening, H.W., Morford, L.L., Inman-Wood, S.L., Fukumura, M. and Vorhees, C.V. (2001) 3,4-Methylenedioxymethamphetamine (Ecstasy)-Induced Learning and Memory Impairments Depend on the Age of Exposure during Early Development. Journal of Neuroscience, 21, 3228-3235.

[47] Aguirre, N., Barrionuevo, M., Lasheras, B. and Del Río, J. (1998) The Role of Dopaminergic Systems in The Perinatal Sensitivity to 3,4-MethylenedioxymethamphetamineInduced Neurotoxicity in Rats. Journal of Pharmacology and Experimental Therapeutics, 286, 1159-1165.

[48] Kelly, P.A.T., Ritchie, I.M., Quate, L., McBean, D.E. and Olverman, H.J. (2002) Functional Consequences of Perinatal Exposure to 3,4-Methylenedioxymethamphetamine in Rat Brain. British Journal of Pharmacology, 137, 963-970. https://doi.org/10.1038/sj.bjp.0704961

[49] Klomp, A., den Hollander, B., de Bruin, K., Booij, J. and Reneman, L. (2012) The Effects of Ecstasy (MDMA) on Brain Serotonin Transporters are Dependent on Age-Of-First Exposure in Recreational Users and Animals. PLOS ONE, 7, e47524. https://doi.org/10.1371/journal.pone.0047524

[50] Meyer, J.S. and Ali, S.F. (2002) Serotonergic Neurotoxicity of MDMA (Ecstasy) in 
the Developing Rat Brain. Annals of the New York Academy of Sciences, 965, 373-380. https://doi.org/10.1111/j.1749-6632.2002.tb04179.x

[51] Meyer, J.S., Grande, M., Johnson, K. and Ali, S.F. (2004) Neurotoxic Effects of MDMA (Ecstasy) Administration to Neonatal Rats. International Journal of Developmental Neuroscience, 22, 261-271.

[52] Spear, L.P. (2016) Consequences of Adolescent Use of Alcohol and Other Drugs: Studies Using Rodent Models. Neuroscience and Biobehavioral Reviews, 70, 228243.

[53] United Nations Office on Drugs and Crime (2016) United Nations World Drug Report. http://www.unodc.org/documents/AnnualReport2015/Annual_Report_2016_WEB. pdf

[54] United States National Institute of Drug Abuse (2016) MDMA (Ecstasy/Molly). https://www.drugabuse.gov/publications/drugfacts/mdma-ecstasymolly

[55] Monitoring the Future (2016) National Survey Results on Drug Use 1975-2016. http://www.monitoringthefuture.org//pubs/monographs/mtf-overview2016.pdf

[56] United States National Institute of Drug Abuse (2016) National Survey of Drug Use and Health. United States National Institutes of Health. https://nsduhweb.rti.org/respweb/homepage.cfm

[57] Halpern, P., Moskovich, J., Avrahami, B., Bentur, Y., Soffer, D. and Peleg, K. (2011) Morbidity Associated with MDMA (Ecstasy) Abuse: Survey of Emergency Department Admissions. Human and Experimental Toxicology, 30, 259-266. https://doi.org/10.1177/0960327110370984

[58] Liechti, M.E., Kunz, I. and Kupferschmidt, H. (2005) Acute Medical Problems Due to Ecstasy Use: Case-Series of Emergency Department Visits. Swiss Medical Weekly, 135, 652-657.

[59] McAleer, L.M., Schallert, T. and Duvauchelle, C.L. (2013) Weekend Ecstasy Use Disrupts Memory in Rats. Neuroscience Letters, 549, 173-176.

[60] Institute of Laboratory Animal Research, Commission on Life Sciences (2011) Guide for the Care and Use of Laboratory Animals. 8th Edition, National Academies Press, Washington DC.

[61] Hartman, R.E., Lee, J.M., Zipfel, G.J. and Wozniak, D.F. (2005) Characterizing Learning Deficits and Hippocampal Neuron Loss Following Transient Global Cerebral Ischemia in Rats. Brain Research, 1043, 48-56.

[62] IBM SPSS Statistics for Windows (Version 23.0). Computer Software, IBM Corp, Armonk.

[63] Gravetter, F.J. and Forzano, L.-A.B. (2016) Research Methods for the Behavioral Sciences. 5th Edition, Cengage, Stamford.

[64] Van der Staay, F.J. (2002) Assessment of Age-Associated Cognitive Deficits in Rats: A Tricky Business. Neuroscience and Biobehavioral Reviews, 26, 753-759.

[65] Sabolek, H.R., Bunce, J.G. Giuliana, D. and Chrobak, J.J. (2004) Within-Subject Memory Decline in Middle-Aged Rats: Effects of Intraseptal Tacrine. Neurobiology of Aging, 25, 1221-1229.

[66] Casey, B.J., Giedd, J.N. and Thomas, K.M. (2000) Structural and Functional Brain Development and Its Relation to Cognitive Development. Biological Psychology, 54, 241-257.

[67] Piper, B.J. and Meyer, J.S. (2004). Memory Deficit and Reduced Anxiety in Young Adult Rats Given Repeated Intermittent MDMA Treatment during the Periadoles- 
cent Period. Pharmacology, Biochemistry and Behavior, 79, 723-731.

[68] Andrade, R. and Beck, S.G. (2010) Cellular Effects of Serotonin in the CNS. In: Müller, C. and Jacobs, B., Eds., Handbook of Behavioral Neurobiology of Serotonin, Academic Press, London, 219-231.

[69] Sturman, D.A. and Moghaddam, B. (2011) The Neurobiology of Adolescence: Changes in Brain Architecture, Functional Dynamics, and Behavioral Tendencies. Neuroscience and Biobehavioral Reviews, 35, 1704-1712.

[70] Whitaker-Azmitia, P.M. (2010) Serotonin and Development. In: Müller, C. and Jacobs, B., Eds., Handbook of Behavioral Neurobiology of Serotonin, Academic Press, London, 309-323.

[71] Sisk, C.L. and Zehr, J.L. (2005) Pubertal Hormones Organize the Adolescent Brain and Behavior. Frontiers in Neuroendocrinology, 26, 163-174.

[72] Cadoni, C., Solinas, M., Pisanu, A., Zernig, G., Acquas, E. and Di Chiara, G. (2005) Effect of 3,4-Methylendioxymethamphetamine (MDMA, "Ecstasy") on Dopamine Transmission in the Nucleus Accumbens Shell and Core. Brain Research, 1055, 143-148.

[73] Lopez-Rodriguez, A.B., Llorente-Berzal, A., Garcia-Segura, L.M. and Viveros M.P. (2013) Sex Dependent Long-Term Effects of Adolescent Exposure to THC and/or MDMA on Neuroinflammation and Serotoninergic and Cannabinoid Systems in Rats. British Journal of Pharmacology, 171, 1435-1447.

https://doi.org/10.1111/bph.12519

[74] Orio, L., O’Shea, E., Sanchez, V., Pradillo, J.M., Escobedo, I., Camarero, J., Moro, M.A., Green, A.R. and Colado, M.I. (2004) 3,4 -Methylenedioxymethamphetamine Increases Interleukin- $\beta$ Levels and Activates Microglia in Rat Brain: Studies on the Relationship with Acute Hyperthermia and 5-HT Depletion. Journal of Neurochemistry, 89, 1445-1453. https://doi.org/10.1111/j.1471-4159.2004.02443.x

[75] Morley-Fletcher, S., Bianchi, M., Gerra, G. and Laviola, G. (2002) Acute and Carryover Effects in Mice of MDMA (Ecstasy) Administration during Periadolescence. European Journal of Pharmacology, 448, 31-38.

[76] Bull, E.J., Hutson, P.H. and Fone, K.C.F. (2004) Decreased Social Behaviour Following 3,4-Methylenedioxymethamphetamine (MDMA) Is Accompanied by Changes in 5-HT2A Receptor Responsivity. Neuropharmacology, 46, 202-210.

[77] Green, A.R., Mechan, A.O., Elliott, J.M., O’Shea, E. and Colado, M.I. (2003) The Pharmacology and Clinical Pharmacology of 3,4-Methylenedioxymetham phetamine (MDMA, “Ecstasy”). Pharmacological Reviews, 55, 463-508. https://doi.org/10.1124/pr.55.3.3

[78] Modgil, S., Lahiri, D.K., Sharma, V.L. and Anand, A. (2014) Role of Early Life Exposure and Environment on Neurodegeneration: Implications on Brain Disorders. Translational Neurodegeneration, 3, 9. https://doi.org/10.1186/2047-9158-3-9

[79] Abad, S., Ramon, C., Pubill, D., Camarasa, J., Camins, A. and Escubedo, E. (2016) Adolescent Exposure to MDMA Induces Dopaminergic Toxicity in Substantia Nigra and Potentiates the Amyloid Plaque Deposition in the Striatum of APPswe/ PS1dE9 Mice. Biochimica et Biophysica Acta, 1862, 1815-1826.

[80] Barnham, K.J., Masters, C.L. and Bush, A.I. (2004) Neurodegenerative Diseases and Oxidative Stress. Nature Reviews Drug Discovery, 3, 205-214. https://doi.org/10.1038/nrd1330

[81] Federico, A., Cardaioli, E., Da Pozzo, P., Formichi, P., Gallus, G.N. and Radi, E. (2012) Mitochondria, Oxidative Stress and Neurodegeneration. Journal of the Neurological Sciences, 322, 254-262. 
[82] Ikeda, A., Sekiguchi, K., Fujita, K., Yamadera, H. and Kog, Y. (2005) 5-MethoxyN,N-Diisopropyltryptamine-Induced Flashbacks. American Journal of Psychiatry, 162, 815. https://doi.org/10.1176/appi.ajp.162.4.815

[83] Wilson, J.M., McGeorge, F., Smolinske, S. and Meatherall, R. (2005) A Foxy Intoxication. Forensic Science International, 148, 31-36.

[84] Meatherall, R. and Sharma, P. (2003) Foxy, a Designer Tryptamine Hallucinogen. Journal of Analytic Toxicology, 27, 313-317. https://doi.org/10.1093/jat/27.5.313

[85] Sitaram, B.R., Lockett, L., Blackman, G.L. and McLeod, W.R. (1987) Urinary Excretion of 5-Methoxy-N,N Dimethyltryptamine, N,N-Dimethyltryptamine and Their N-Oxides in the Rat. Biochemical Pharmacology, 36, 2235-2237.

[86] Smolinske, S.C., Rastogi, R. and Schenkel, S. (2005) Foxy Methoxy: A New Drug of Abuse. Journal of Medical Toxicology, 7, 23-25. https://doi.org/10.1007/BF03160901

[87] Nagai, F., Nonaka, R. and Kamimura, K.S.H. (2007) The Effects of Non-Medically Used Psychoactive Drugs on Monoamine Neurotransmission in Rat Brain. European Journal of Pharmacology, 559, 132-137.

[88] Nakagawa, T. and Kaneko, S. (2008) Neuropsychotoxicity of Abused Drugs: Molecular and Neural Mechanisms of Neurotoxicity Induced by Methamphetamine, 3,4-Methylenedioxymethamphetamine (Ecstasy), and 5-methoxy-N, N-diisopropyltryptamine (Foxy). Journal of Pharmacological Sciences, 106, 2-8. https://doi.org/10.1254/jphs.FM0070141

[89] Puerta, E. and Aguirre, N. (2011) Methylenedioxymethamphetamine (MDMA, "Ecstasy"): Neurodegeneration versus Neuromodulation. Pharmaceuticals, 4, 992-1018. https://doi.org/10.3390/ph4070992

[90] Lew, R., Sabol, K.E., Chou, C., Vosmer, G.L., Richards, J. and Seiden, L.S. (1996) Methylenedioxymethamphetamine-Induced Serotonin Deficits Are Followed by Partial Recovery over a 52-Week Period. Part II: Radioligand Binding and Autoradiography Studies. Journal of Pharmacology and Experimental Therapeutics, 276, 855-865.

[91] Sabol, K.E., Lew, R., Richards, J.B., Vosmer, G.L. and Seiden, L.S. (1996) Methylenedioxymethamphetamine-Induced Serotonin Deficits are Followed by Partial Recovery Over a 52-Week Period. Part I: Synaptosomal Uptake and Tissue Concentrations. Journal of Pharmacology and Experimental Therapeutics, 276, 846-854.

[92] Scanzello, C.R., Hatzidimitriou, G., Martello, A.L., Katz, J.L. and Ricaurte, G.A. (1993) Serotonergic Recovery after (+/-)3,4-(Methylenedioxy) Methamphetamine Injury: Observations in Rats. Journal of Pharmacology and Experimental Therapeutics, 264, 1484-1491.

[93] Brennan, K.A. and Schenk, S. (2006) Initial Deficit and Recovery of Function after MDMA Preexposure in Rats. Psychopharmacology, 184, 239-246. https://doi.org/10.1007/s00213-005-0278-y

[94] Fischer, C., Hatzidimitriou, G., Wlos, J., Katz, J. and Ricaurte, G. (1995) Reorganization of Ascending 5-HT Axon Projections in Animals Previously Exposed to the Recreational Drug (+/-)3,4-Methylenedioxymethamphetamine (MDMA, “Ecstasy”). Journal of Neuroscience, 15, 5476-5485.

[95] Reneman, L., Endert, E., de Bruin, K., Lavalaye, J., Feenstra, M.G., de Wolff, F.A. and Booij, J. (2002) The Acute and Chronic Effects of MDMA ("Ecstasy") on Cortical 5- $\mathrm{HT}_{2 \mathrm{~A}}$ Receptors in Rat and Human Brain. Neuropsychopharmacology, 26, 387-396.

[96] Huff, C.L. (2016) MDMA and Glutamate: Implications for Hippocampal GABAer- 
gic Neurotoxicity. Doctoral Dissertation. http://rave.ohiolink.edu/etdc/view?acc_num=ucin1460444662

[97] Huff, C.L., Morano, R.L., Herman, J.P., Yamamoto, B.K. and Gudelsky, G.A. (2016) MDMA Decreases Glutamic Acid Decarboxylase (GAD) 67-Immunoreactive Neurons in the Hippocampus and Increases Seizure Susceptibility: Role for Glutamate. Neurotoxicology, 57, 282-290.

[98] McCann, U.D. and Ricaurte, G.A. (2004) Amphetamine Neurotoxicity: Accomplishments and Remaining Challenges. Neuroscience and Biobehavioral Reviews, 27, 821-826.

[99] O’Hearn, E., Battaglia, G., De Souza, E.B., Kuhar, M.J. and Molliver, M.E. (1988) Methylenedioxyamphetamine (MDA) and Methylenedioxymethamphetamine (MDMA) Cause Selective Ablation of Serotonergic Axon Terminals in Forebrain: Immunocytochemical Evidence for Neurotoxicity. Journal of Neuroscience, 8, 2788-2803.

[100] Molliver, M.E., Berger, U.V., Mamounas, L.A., Molliver, D.C., O’Hearn, E. and Wilson, M.A. (1990) Neurotoxicity of MDMA and Related Compounds: Anatomic Studies. Annals of the New York Academy of Sciences, 600, 649-661. https://doi.org/10.1111/j.1749-6632.1990.tb16916.x

[101] Thomasius, R., Zapletalova, P., Petersen, K., Buchert, R., Andresen, B., Wartberg, L., Nebeling, B. and Schmoldt, A. (2006) Mood, Cognition and Serotonin Transporter Availability in Current and Former Ecstasy (MDMA) Users: The Longitudinal Perspective. Journal of Psychopharmacology, 20, 211-225. https://doi.org/10.1177/0269881106059486

[102] Reneman, L., Booij, J., de Bruin, K., Reitsma, J.B., de Wolff, F.A., Gunning, W.B., den Heeten, G.I. and van den Brink, W. (2001) Effects of Dose, Sex, and Long-Term Abstention from Use on Toxic Effects of MDMA (Ecstasy) on Brain Serotonin Neurons. The Lancet, 358, 1864-1869.

[103] Thomasius, R., Petersen, K.U., Buchert, R., Andresen, B., Zapletalova, P., Wartberg, L., Nebeling, B. and Schmoldt, A. (2003) Mood, Cognition, and Serotonin Transporter Availability in Current and Former Ecstasy (MDMA) Users. Psychopharmacology, 167, 85-96. https://doi.org/10.1007/s00213-002-1383-9

[104] García-Cabrerizo, R. and García-Fuster, M.J. (2016) Comparative Effects of Amphetamine-Like Psychostimulants on Rat Hippocampal Cell Genesis at Different Developmental Ages. Neurotoxicity, 56, 29-39.

[105] Battaglia, G., Sharkey, J., Kuhar, M.J. and de Souza, E.B. (1991) Neuroanatomic Specificity and Time Course of Alterations in Rat Brain Serotonergic Pathways Induced by MDMA (3,4-Methylenedioxymethamphetamine): Assessment Using Quantitative Autoradiography. Synapse, 8, 249-260.

https://doi.org/10.1002/syn.890080403

[106] Piper, L.P. (2016) Consequences of Adolescent Use of Alcohol and Other Drugs: Studies Using Rodent Models. Neuroscience and Biobehavioral Reviews, 70, 228-243.

[107] Colado, M., Murray, T. and Green, A. (1993) 5-HT Loss in Rat Brain Following 3,4-Methylenedioxymethamphetamine (MDMA), p-Chloroamphetamine and Fenfluramine Administration and Effects of Chlormethiazole and Dizocilpine. British Journal of Pharmacology, 108, 583-589. https://doi.org/10.1111/j.1476-5381.1993.tb12846.x

[108] Colado, M., Williams, J. and Green, A. (1995) The Hyperthermic and Neurotoxic Effects of "Ecstasy" (MDMA) and 3,4-Methylenedioxyamphetamine (MDA) in the Dark Agouti (DA) Rat, a Model of the CYP2D6 Poor Metabolizer Phenotype. Brit- 
ish Journal of Pharmacology, 115, 1281-1289.

https://doi.org/10.1111/j.1476-5381.1995.tb15037.x

[109] Commins, D., Vosmer, G., Virus, R., Woolverton, W., Schuster, C. and Seiden, L. (1987) Biochemical and Histological Evidence that Methylenedioxymethylamphetamine (MDMA) Is Toxic to Neurons in the Rat Brain. Journal of Pharmacology and Experimental Therapeutics, 241, 338-345.

[110] Shankaran, M. and Gudelsky, G.A. (1999). A Neurotoxic Regimen of MDMA Suppresses Behavioral, Thermal and Neurochemical Responses to Subsequent MDMA Administration. Psychopharmacology, 147, 66-72. https://doi.org/10.1007/s002130051143

[111] O’Shea, E., Granados, R., Esteban, B., Colado, M.I. and Green, A.R. (1998) The Relationship between the Degree of Neurodegeneration of Rat Brain 5-HT Nerve Terminals and the Dose and Frequency of Administration of MDMA ("Ecstasy"). Neuropharmacology, 37, 919-926.

[112] Armstrong, B.D. and Noguchi, K.K. (2004) The Neurotoxic Effects of 3,4-Methylenedioxymethamphetamine (MDMA) and Methamphetamine on Serotonin, Dopamine, and GABA-Ergic Terminals: An in Vitro Autoradiographic Study in Rats. Neurotoxicology, 25, 905-914.

[113] Tamburini, I., Blandini, F., Gesi, M., Frenzilli, G., Nigro, M., Giusiani, M., Paparelli, A. and Fornai, F. (2006) MDMA Induces Caspase-3 Activation in the Limbic System but not in Striatum. Annals of the New York Academic of Sciences, 1074, 377-381. https://doi.org/10.1196/annals.1369.037

[114] Warren, M.W., Larner, S.F., Kobeissy, F.H., Brezing, C.A., Jeung, J.A., Hayes, R.L., Gold, M.S. and Wang, K.K. (2007) Calpain and Caspase Proteolytic Markers Co-Localize with Rat Cortical Neurons after Exposure to Methamphetamine and MDMA. Acta Neuropathologica, 114, 277-286. https://doi.org/10.1007/s00401-007-0259-9

[115] Gudelsky, G.A. and Yamamoto, B.K. (2008) Actions of 3,4-Methylenedioxymethamphetamine (MDMA) on Cerebral Dopaminergic, Serotonergic and Cholinergic Neurons. Pharmacology, Biochemistry and Behavior, 90, 198-207.

[116] Catlow, B.J., Badanich, K.A., Sponaugle, A.E., Rowe, A.R., Song, S., Rafalovich, I., Sava, V., Kirstein, C.L. and Sanchez-Ramos, J. (2010) Effects of MDMA ("Ecstasy") during Adolescence on Place Conditioning and Hippocampal Neurogenesis. European Journal of Pharmacology, 628, 96-103.

[117] Canales, J.J. (2010) Comparative Neuroscience of Stimulant-Induced Memory Dysfunction: Role for Neurogenesis in the Adult Hippocampus. Behavioural Pharmacology, 21, 379-393. https://doi.org/10.1097/FBP.0b013e32833e16b6

[118] Darvesh, A.S. and Gudelsky, G.A. (2005) Evidence for a Role of Energy Dysregulation in the MDMA-Induced Depletion of Brain 5-HT. Brain Research, 1056, 168-175.

[119] Quate, L., McBean, D.E., Ritchie, I.M., Olverman, H.J. and Kelly, P.A. (2004) Acute Methylenedioxymethamphetamine Administration: Effects on Local Cerebral Blood Flow and Glucose Utilisation in the Dark Agouti Rat. Psychopharmacology, 173, 287-295. https://doi.org/10.1007/s00213-004-1784-Z

[120] Darvesh, A.S., Yamamoto, B.K. and Gudelsky, G.A. (2005) Evidence for the Involvement of Nitric Oxide in 3,4-Methylenedioxymethamphetamine-Induced Serotonin Depletion in the Rat Brain. Journal of Pharmacology and Experimental Therapeutics, 312, 694-701. https://doi.org/10.1124/jpet.104.074849

[121] Sprague, J.E., Everman, S.L. and Nichols, D.E. (1998) An Integrated Hypothesis for 
the Serotonergic Axonal Loss Induced by 3,4-Methylenedioxymethamphetamine. Neurotoxicology, 19, 427-441.

[122] Downey, L.A. and Loftis, J.M. (2014) Altered Energy Production, Lowered Antioxidant Potential, and Inflammatory Processes Mediate CNS Damage Associated with Abuse of the Psychostimulants MDMA and Methamphetamine. European Journal of Pharmacology, 727, 125-129.

[123] Fantegrossi, W.E., Harrington, A.W., Kiessel, C.L., Eckler, J.R., Rabin, R.A., Winter, J.C., Coop, A., Rice, K.C. and Woods, J.H. (2006) Hallucinogen-Like Actions of 5-Methoxy-N,N-Diisopropyltryptamine in Mice and Rats. Pharmacology, Biochemistry and Behavior, 83, 122-129.

[124] Sogawa, C., Sogawa, N., Tagawa, J., Fujino, A., Ohyama, K., Asanuma, M., Funada, M. and Kitayama, S. (2007) 5-Methoxy-N,N-Diisopropyltryptamine (Foxy), a Selective and High Affinity Inhibitor of Serotonin Transporter. Toxicology Letters, 170, 75-82.

[125] Schaefer, T.L., Skelton, M.R., Herring, N.R., Gudelsky, G.A., Vorhees, C.V. and Williams, M.T. (2008) Short- and Long-Term Effects of (+)-Methamphetamine and (+/-)-3,4-Methylenedioxymethamphetamine on Monoamine and Corticosterone Levels in the Neonatal Rat Following Multiple Days of Treatment. Journal of Neurochemistry, 104, 1674-1685. https://doi.org/10.1111/j.1471-4159.2007.05112.x

[126] Williams, M.T., Schaefer, T.L., Ehrman, L.A., Able, J.A., Gudelsky, G.A., Sah, R. and Vorhees, C.V. (2005) 3,4-Methylenedioxymethamphetamine Administration on Postnatal Day 11 in Rats Increases Pituitary-Adrenal Output and Reduces Striatal and Hippocampal Serotonin without Altering SERT Activity. Brain Research, 1039, 97-107.

[127] Baumann, M.H., Clark, R.D., Franken, F.H., Rutter, J.J. and Rothman, R.B. (2008) Tolerance to 3,4-Methylenedioxymethamphetamine in Rats Exposed to Single High-Dose Binges. Neuroscience, 152, 773-784.

[128] Nash Jr., J.F., Meltzer, H.Y. and Gudelsky, G.A. (1988) Elevation of Serum Prolactin and Corticosterone Concentrations in the Rat after the Administration of 3,4-Methylenedioxymethamphetamine. Journal of Pharmacology and Experimental Therapeutics, 245, 873-879.

[129] Graham, D.L., Herring, N.R., Schaefer, T.L., Vorhees, C.V. and Williams, M.T. (2010) Glucose and Corticosterone Changes in Developing and Adult Rats Following Exposure to ( \pm )-3,4-Methylendioxymethamphetamine or 5-Methoxydiisopropyltryptamine. Neurotoxicology and Teratology, 32, 152-157.

[130] Williams, M.T., Herring, N.R., Schaefer, T.L., Skelton, M.R., Campbell, N.G., Lipton, J.W., McCrea, A.E. and Vorhees, C.V. (2007) Alterations in Body Temperature, Corticosterone, and Behavior Following the Administration of 5-Methoxy-Diisopropyltryptamine ("Foxy") to Adult Rats: A New Drug of Abuse. Neuropsychopharmacology, 32, 1404-1420. https://doi.org/10.1038/sj.npp.1301232

[131] McGaugh, J.L. and Roozendaal, B. (2008) Memory Modulation. In: Menzel, R. and Byrne, J.H., Eds., Learning and Memory. A Comprehensive Resource, Volume 3, Memory Systems, Academic Press, New York, 519-553.

[132] De La Torre, R. and Farré, M. (2004) Neurotoxicity of MDMA (Ecstasy): The Limitations of Scaling from Animals to Humans. Trends in Pharmacological Sciences, 25, 505-508.

[133] Green, A.R., Gabrielsson, J., Marsden, C.A. and Fone, K.C. (2009) MDMA: On the Translation from Rodent to Human Dosing. Psychopharmacology, 204, 375-378. https://doi.org/10.1007/s00213-008-1453-8 
[134] Hatzidimitriou, G., McCann, U.D. and Ricaurte, G.A. (1999) Altered Serotonin Innervation Patterns in the Forebrain of Monkeys Treated with (+/-)3,4-Methylenedioxymethamphetamine Seven Years Previously: Factors Influencing Abnormal Recovery. Journal of Neuroscience, 19, 5096-5107.

[135] Mechan, A., Yuan, J., Hatzidimitriou, G., Irvine, R.J., McCann, U.P. and Ricaurte, G.A. (2006) Pharmacokinetic Profile of Single and Repeated Oral Doses of MDMA in Squirrel Monkeys: Relationship to Lasting Effects on Brain Serotonin Neurons. Neuropsychopharmacology, 31, 339-350. https://doi.org/10.1038/sj.npp.1300808

[136] Booij, L., Soucy, J., Young, S., Regoli, M., Gravel, P., Diksic, M., Leyton, M., Pihl, R.O. and Bebkelfat, C. (2014) Brain Serotonin Synthesis in MDMA (Ecstacy) Polydrug Users: an Alpha [(11)C]Methyl- ${ }_{L}$-Tryptophan Study. Journal of Neurochemistry, 131, 634-644. https://doi.org/10.1111/jnc.12826

[137] Fields, R.D. (2014) NIH Policy: Mandate Goes too Far. Nature, 510, 340. https://doi.org/10.1038/510340a

[138] Becker, J.B., Prendergast, B.J. and Liang, J.W. (2016) Female Rats Are not More Variable than Male Rats: A Meta-Analysis of Neuroscience Studies. Biology of Sex Differences, 7, 34. https://doi.org/10.1186/s13293-016-0087-5

[139] Clayton, J.A. and Collins, F.S. (2014) Policy: NIH to Balance Sex in Cell and Animal Studies. Nature, 509, 282-283. https://doi.org/10.1038/509282a

[140] Allott, K. and Redman, J. (2007) Are There Sex Differences Associated with the Effects of Ecstasy/3,4-Methylenedioxymethamphetamine (MDMA)? Neuroscience \& Biobehavioral Reviews, 31, 327-347.

[141] Cadet, J.D., Ladenheim, B., Baum, I., Carlson, E. and Epstein, C. (1994) CuZnSuperoxide Dismutase (CuZnSOD) Transgenic Mice Show Resistance to the Lethal Effects of Methylenedioxyamphetamine (MDA) and of Methylenedioxymethamphetamine (MDMA). Brain Research, 655, 259-262.

[142] Fonsart, J., Menet, M.-C., Declèves, X., Galons, H., Crété, D., Debray, M., Scherrmann, J.-M. and Noble, F. (2008) Sprague-Dawley Rats Display Metabolism-Mediated Sex Differences in the Acute Toxicity of 3,4-Methylenedioxymethamphetamine (MDMA, Ecstasy). Toxicology and Applied Pharmacology, 230, 117-125.

[143] Koenig, J., Lazarus, C., Jeltsch, H., Ben, H.S., Riegert, C., Kelche, C., Jones, B.C. and Cassel, J.C. (2005) MDMA (Ecstasy) Effects in Pubescent Rats: Males Are More Sensitive than Females. Pharmacology, Biochemistry, and Behavior, 81, 635-644.

[144] Hurst, J.L., Barnard, C.J., Nevison, C.M. and West, C.D. (1997) Housing and Welfare in Laboratory Rats: Welfare Implications of Isolation and Social Contact among Caged Males. Animal Welfare, 6, 329-347.

[145] Võikar, V., Polus, A., Vasar, E. and Rauvala, H. (2005) Long-Term Individual Housing in C57BL/6J and DBA/2 Mice: Assessment of Behavioral Consequences. Genes, Brain and Behavior, 4, 240-252. https://doi.org/10.1111/j.1601-183X.2004.00106.x 
Submit or recommend next manuscript to SCIRP and we will provide best service for you:

Accepting pre-submission inquiries through Email, Facebook, LinkedIn, Twitter, etc. A wide selection of journals (inclusive of 9 subjects, more than 200 journals)

Providing 24-hour high-quality service

User-friendly online submission system

Fair and swift peer-review system

Efficient typesetting and proofreading procedure

Display of the result of downloads and visits, as well as the number of cited articles Maximum dissemination of your research work

Submit your manuscript at: http://papersubmission.scirp.org/

Or contact jbbs@scirp.org 